Revista aSEPHallus de Orientação Lacaniana Núcleo Sephora de Pesquisa sobre o Moderno e o Contemporâneo ISSN 1809 - $709 \mathrm{X}$

Para bom entendedor meia psicanálise não basta

Fernanda Costa-Moura

Professora do Programa de Pós-graduação em Teoria Psicanalítica da Universidade Federal do Rio de Janeiro

Bolsista de Produtividade em Pesquisa do CNPq

Psicanalista, membro do Tempo Freudiano Associação Psicanalítica

Doutora em Psicologia Clínica - PUC-Rio, 2000

E-mail: costamouraf@gmail.com

Resumo: O trabalho aborda o que pode ser a posição do analista no laço social por relação ao problema do gozo. Partindo da emergência de um chiste no Brasil do final dos anos 70 e das análises de Lacan quanto ao fundamento econômico do gozo, procura-se discernir o que seria a intervenção da psicanálise quanto ao gozo na contemporaneidade e, especialmente, na conjuntura atual do país.

Palavras-chave: psicanálise; sujeito; gozo; chiste; "Lei de Gerson".

\begin{abstract}
À bon compreneur demi-psychanalyse ne suffit pas
Le travail concerne à ce qui peut être la position de l'analyste dans le lien social par rapport au problème de la jouissance. En partant de l'émergence d'un mot d'esprit au Brésil à la fin des années 70 et des analyses de Lacan en ce qui concerne le fondement économique de la jouissance, on cherche à discerner ce qui serait l'intervention de la psychanalyse vers la jouissance dans la contemporaneité et, plutôt, dans la conjoncture actuelle du pays.
\end{abstract}

Mots-clés: psychanalyse; sujet; jouissance; mot d'esprit; "Loi de Gerson".

To a good reader half psychoanalysis is not enough

The article approaches what can be the position of the analyst in the social tie in relation to the problem of jouissance. Starting from the emergence of a witticism in Brazil in the late 1970s and Lacan's analysis of the economic fundament of jouissance, we try to discern what would be the intervention of psychoanalysis toward the jouissance in contemporaneity and, especially, in the current situation of the country.

Keywords: psychoanalysis; subject; jouissance; witticism; "Law of Gerson". 


\section{Para bom entendedor meia psicanálise não basta}

\section{Fernanda Costa-Moura}

Lacan o disse de variadas maneiras: um discurso tem condições e é mesmo idêntico às suas condições (Lacan, 1968-1969/2008, p. 31). E se a psicanálise é um discurso, isso implica que ela está ligada inevitavelmente às inflexões, aos tempos do discurso.

Já discuti anteriormente a posição de Lacan frente ao fracasso da psicanálise ${ }^{1}$ procurando cernir o que por aí se indicava a propósito da posição do analista frente ao real (Costa-Moura \& Lo Bianco, 2006; Costa-Moura, 2010). Já trabalhei igualmente a questão colocada por Lacan a propósito da existência da psicanálise ${ }^{2}$, entendendo que a dificuldade neste caso concernia à psicanálise poder cernir, no real, o objeto estrutural que constitui o sujeito e ao mesmo tempo determina o ponto em que nos encontramos do discurso e da civilização (Costa-Moura \& Fernandes, 2011). Nestes trabalhos procurei argumentar que se a psicanálise puder ainda prevalecer como discurso, isso implicará, decerto, que ela possa tornar tangíveis os efeitos da incidência da ciência e do capitalismo em sua configuração atual, sobre o campo do sujeito e o laço social. Porém, ainda que apostemos nisso - nesta operação que, como dissemos acima, só pode se dar no real e, portanto, só pode se realizar como práxis e não como saber, como elucubração -, resta interrogar o que pode ser a intervenção da psicanálise neste domínio. Visando essa diretriz, o presente trabalho busca discernir o que constitui a intervenção do analista no laço social contemporâneo por relação ao problema do gozo.

Analisando o que acossa o sujeito, Freud (1915/1976) pode formular que a pulsão atua como força constante, e Lacan (1968-1969/2008), que a satisfação que o sujeito extrai dela é real. Seguindo esta direção, a psicanálise demarcou a satisfação paradoxal que sobrevém da pulsão como exigência incessante de trabalho e que tende a se repetir, obturando o lugar do sujeito no ponto mesmo onde incide para ele a falta constitutiva de objeto que o convoca ao desejo. Uma satisfação, cuja substância é de gozo, que se dá por essa espécie de regozijo, que não se realiza nem no plano da obtenção do prazer, nem no da consecução dos ideais, e confere ao sujeito a única consistência que Ihe diz respeito - e que é tão peculiar. Porém, do gozo, como diz Lacan (1972-1973/1975, p. 9), "eu não quero saber nada"3. Ao contrário, como veremos, é da estrutura do gozo se repetir e se infinitizar, alijando o sujeito do campo do desejo, que faz a sua condição. Assim, importa perguntar: como uma intervenção pode situar nossa posição, o ponto em que nos encontramos por relação ao gozo - do qual não queremos saber? Especialmente no Brasil de hoje, onde tantas vozes clamam a cada instante, serem detentoras da melhor versão, da "verdade mais verdadeira", da opção mais justa; como situar a presença de uma perda ineliminável que nos atravessa a todos, de modo a reabrir a chance de emergência do sujeito na dimensão do desejo - em contraposição à toda nossa tendência e nossas ambições? 


\section{Um chiste?}

Para abordar a particularidade da presença da psicanálise como discurso em relação à cultura e ao Brasil contemporâneo, partiremos de algo que emergiu com um efeito de chiste e produziu uma abertura, que revelou um traço tão distintivo quanto incômodo, mas no qual pudemos nos reconhecer de imediato, para grande comoção da nação.

Trata-se de um episódio acontecido no final dos anos 70, que consistiu na enunciação pública - e inesperada - daquilo que ficaria conhecido como a "Lei de Gerson". A origem é conhecida: tratava-se de uma propaganda criada pela Caio Domingues \& Associados, para divulgar a marca de cigarros Vila Rica no cinema e na televisão 4 . 0 anúncio apresentava o jogador Gerson, como o "cérebro do time campeão da Copa do mundo de 70" e este apregoava a vantagem de pagar menos por um produto ('o Vila') que lhe dava tudo o que se quer de um 'bom cigarro'. Finalmente, olhando diretamente para a câmera e aproximando o corpo como se para fazer uma confidência, Gerson concluía: "Gosto de levar vantagem em tudo, certo? Leve vantagem você também, leve Vila Rica!".

A partir daí, a chamada "Lei de Gerson" passou a designar a prática de buscar obter vantagem, independente de questões éticas ou morais. Mas, mais do que isso, a enunciação desta prática como um princípio a ser seguido, demarcou publicamente um traço pouco lisonjeiro que passou a ser visto como característico da população e do 'caráter nacional' - numa interpretação que foi impulsionada, além de tudo, pelas notícias sobre corrupção na política brasileira que circulariam cada vez mais daí em diante.

Pouco depois o jogador anunciou ter se arrependido por ter associado sua imagem ao anúncio que determinou que comportamentos, os mais controversos, fossem vinculados ao seu nome. Tentou-se inclusive fazer um 'desmentido' na forma de um segundo anúncio, onde o mesmo Gerson tentava 'explicar' que "Levar vantagem não é passar ninguém para trás, é chegar na frente". Mas essa frase não ficou na cultura. E até hoje a língua divulga e a população utiliza a expressão "Lei de Gérson" como sinônimo de banalização da lei moral, e desrespeito às regras de convívio para a obtenção de benefícios pessoais.

Mas como foi que a frase publicitária, que como toda frase publicitária, diga-se de passagem, pretende ser "esperta", "non-dupe", acabou tendo um efeito de chiste entre nós? Nossa aposta é que foi a enunciação de Gerson, expressa no olhar direto para a câmera e, sobretudo, na escolha uma inciativa que, sabe-se hoje, foi do próprio jogador, não estando prevista no roteiro do comercial - de acrescentar à frase original ("Gosto de levar vantagem em tudo...") um pequeno comentário; um "caco"5 pode se dizer, na forma de uma interrogação ("...certo?). Uma interrogação que ao mesmo tempo solicitava a concordância e até a autorização do ouvinte, mas que, sobretudo, já incluía e contava com a presença do mais pleno, do mais íntimo assentimento do espectador ao princípio geral que estava sendo veiculado.

Como acontece na irrupção de uma formação do inconsciente, pode-se pensar que foi este pequeno cacoete do sujeito - um comparecimento repentino, incalculado, pulsional; uma aparição 
do corpo que presentifica o desejo num registro fora dos ideais -, que desconcertou e, ainda hoje, nos pega, por assim dizer, em flagrante. Desnudando, exibindo, assinalando na sanção que a peça obtém imediatamente de nós, não apenas a cupidez recalcada da nação, mas, igualmente, a adesão de cada um ao gozo - que ali, quedava revelada.

Falando de outro chiste coletado por Freud, aquele que ficou conhecido como o "Familionário", Lacan sublinha o efeito de discurso implicado na produção de uma tirada espirituosa (Lacan, 1968-1969/2008): um chiste só pode se produzir e ter alcance na medida em que nele se articulam os elementos exatos, capazes de rearranjar algo na esfera semântica do discurso seguindo os ditames do jogo significante. Mas, além disso, sua produção apoia-se em algo que Freud (1905/1976) já identificara como "a função econômica" do chiste. A saber, aquilo que permite uma "economia psíquica", um ganho suplementar de prazer que se obtém no curto circuito que se estabelece ali onde o sujeito diz (ou ouve, tanto faz - no chiste estamos todos implicados), mas se escusa de pagar pela verdade que emerge por esta via e que põe em movimento a cadeia significante. Esta "economia" de um pagamento que seria devido e que é ao mesmo tempo elisão da perda do sujeito, constitui o "sintoma". Ou mais precisamente, "o modo como cada um sofre em sua relação com o gozo, porquanto se insere nela pela função do mais-de-gozar" (Lacan, 19681969/2008, p. 40).

Se há desconcerto, portanto, quando o enunciado desta "Lei de Gerson" faz o nosso laço social aparecer no discurso, se há um deslocamento tal que, a partir daí o sujeito pode se dizer, o Brasil não goza mais tão inocentemente como antes, isso não se dá meramente pelo sentido, nem apenas pela construção significante. Isso se dá porque uma frase que nos lê pode ser enunciada e incidir, desarticulando (ao menos temporariamente) o gozo que sobrevive ali enquistado e o recalque que mantém este mesmo gozo. Diante desse dizer novo que atinge o sujeito e os que estão com ele neste laço, o riso não falta (embora nervoso). E se por outro lado, o efeito de chiste não deixa de ter alcance para nós, ainda hoje, é porque estamos todos implicados na cativação exercida pelo gozo que ali é alardeado. O gozo de colocar à frente nosso próprio interesse - interesse econômico, pecuniário, mas também de satisfação pulsional, de gozo -, extraindo-o de um jogo com as Leis da linguagem, quando estas justamente deveriam regulá-lo.

Eis portanto a nossa condição de sujeitos assujeitados. Tão mais precária, mais prisioneira, quanto mais sofisticada. Quanto mais nos tornamos 'bons entendedores' do 'sistema'; quanto mais nos aperfeiçoamos em "levar vantagem em tudo", mais e mais estamos obrigados a produzirmos satisfação (será possível dizer que é nossa, essa satisfação?) excertando uma mais-valia de gozo sob comando da máquina do capital.

\section{Uma função econômica}

Lacan não se enganava quanto a isto. E observando que o advento do sujeito como desejo se equaciona por relação ao problema do gozo, afeito menos à realização dos ideais do que à 
satisfação da pulsão, foi buscar em Marx um fundamento para falar das amarras econômicas implicadas no gozo que nos concerne.

Para Lacan foi Marx quem conseguiu demonstrar como o valor que se agrega ao capital durante o processo produtivo sob a forma da mais-valia é um efeito necessário e, mais ainda, é um "sintoma" (com potência de portar a verdade) da articulação do dispositivo capitalista. Segundo Marx a mais-valia transforma a força de trabalho em uma mercadoria especial, uma "mercadoria cujo valor de uso possui a propriedade peculiar de ser fonte de valor" (Marx, 1867[1890]/1998, p. 197). Dado disso, o valor de uso da força de trabalho passa a ser cobiçado e consumido justamente na forma de um "excedente" de trabalho "não pago", que ela é capaz de produzir. Dito de outro modo, o valor a ser explorado na força de trabalho, passa a se concentrar na possibilidade que a força de trabalho detém - mas que o trabalhador não possui - de produzir um a mais de gozo (de mercadoria) que é embutido em seu valor de troca.

Com isso, ao vender sua força de trabalho no mercado, o trabalhador vende algo que será pago, mas entrega também um tanto a mais de gozo que não será recuperado jamais. Marx foi sensível ao fato de que, em função desta defasagem estrutural, malgrado o fato de que esse excedente que o trabalhador proporciona ao mercado a rigor não lhe pertence (uma vez que ele já vendeu sua força de trabalho), mesmo assim, ele o perde na operação. Ou por outra, este algo a mais que não Ihe pertence e que ele proporciona ao Outro no ato de sua inscrição no sistema, recai para ele como perda.

Por outras vias, e desde sempre Freud também divisou um objeto perdido na origem do sujeito. No contexto do seminário De um Outro ao outro Lacan retoma esta perda inaugural como a "renuncia ao gozo" que se encontra implicada no advento do sujeito a partir da linguagem (Lacan, 1968-1969/2008, p. 113). Empenhamos algo, entregamos algo ao Outro; e mesmo, como salienta Lacan (1964/1985), é forçoso escolher esta perda para entrar na linguagem, ou, nos termos de Freud, para responder às "urgências da vida" (Freud, 1895[1950]/1996).

No laço capitalista, vivemos a perda implicada na estrutura da atividade humana, como expropriação. É esta marca de expropriação - ou, nos termos de Lacan, de renúncia ao gozo efetuada sob o comando do significante na entrada do sujeito na linguagem - que aciona o arrebatamento que experimentamos quando se ergue para nós um objeto (qualquer) que por assim dizer, "incorpora" a parte que foi expropriada do nosso trabalho e que experimentamos como o "pedaço carnal arrancado de nós mesmos" (Lacan, 1962-1963/2005, p. 237) que precisamos reaver a qualquer custo. Por sua vez é esta tentativa infinitamente reiterada; é esta obstinação do sujeito em recuperar o pequeno quinhão de gozo do qual ele terá sido expropriado, que suscita a operação, através da qual o valor de troca da mercadoria chega a ofuscar, para nós, a importância que, em princípio (justamente numa economia 'pré-capitalista') caberia ao valor de uso; consolidando o capitalismo propriamente dito. 
Sobre a mais-valia, então, Lacan, "decalca", como ele mesmo indica (Lacan, 19681969/2008, p. 29), o conceito de mais-de-gozar enquanto a "função adquirida pelo objeto $d$ " (Lacan, 1968-1969/2008, p. 29), na conjuntura moderna de absolutização do mercado, cujos primeiros indícios, Marx destacou. Uma função cuja operação se assenta, não na produção de riqueza, que resto é sempre limitada, contábil (e em última análise, tributável, isto é, paga-se alguma coisa por ela), e sim na produção de um gozo a mais - virtualmente ilimitado e impossível de contabilizar. A partir dessa retomada das premissas estabelecidas por Marx, e análise de sua incidência no campo do sujeito, Lacan pode ler o modo de produção capitalista - baseado na produção de um excesso que deve ser gasto no menor tempo possível, de modo que mais excesso seja produzido e, a seguir, consumido incessantemente - como uma economia do gozo. Um modo específico de distribuir e ligar o sujeito ao gozo, que na prática discursiva capitalista assume a forma da mercadoria.

Lacan concebe, com efeito, tanto o "fetiche da mercadoria" 6 quanto o mais-de-gozar como efeitos necessários de nossa relação ao significante, independente de qualquer esfera de pensamento ou cultural que tenha decidido produzi-los. E esta proposição modifica drasticamente as questões colocadas pelo ideário marxiano. Juntando-se a Freud no debate mais amplo que já fora encaminhado em artigos como "O mal-estar na civilização" (Freud, 1930/1976) e "Análise terminável e interminável" (Freud, 1937/1976), o empenho de Lacan para levar em consideração a dimensão estrutural envolvida na produção da satisfação pulsional e de nossa relação com os objetos permite que o gozo, como problema, seja situado não apenas num registro psicológico, individual, patológico, e sim como uma consequência necessária do processo econômico. Parafraseando Marx, se poderia dizer que o gozo existe 'apenas por haver capacidade de produzi-lo' e haver 'quem o consuma numa escala que paga sua produção'. Sem esquecermo-nos do que o próprio Marx já demonstrou, ou seja, que tal relação, aparentemente instável e contingente, é capaz de acionar um processo complexo, global e extremamente resistente aos mais variados tipos de esforços empreendidos para controlar sua abrangência.

Quando fala de uma "fantasmagoria" (Marx, 1867[1890]/1998, p. 94) que comanda nossas relações com a "coisa-mercadoria", deixando entrever esta atração trágica que os itens de consumo podem exercer sobre nós, Marx não está tão distante de Freud que sempre relacionou a questão dos empreendimentos e apetites humanos não à necessidade, mas à dimensão pulsional - que é também regida, de forma implacável, por fatores econômicos. Porém, para Marx o trabalhador não goza do que ele efetivamente pode produzir, por não dispor dos meios de produção, enquanto que, para Freud, um sujeito não goza do que se consubstancia desde sempre como das Ding, aquilo que viria fazer coincidir todos os objetos da realidade e da fantasia, e que nunca chegamos a alcançar o que determina que o sujeito permaneça sempre constrangido a desejar.

Por não divisar a pregnância desta condição do sujeito, Marx incorre na posição que Freud descreve, em sua conferência sobre a Weltanschauung como uma "tentação"; a tentação de alterar as esferas econômicas "pela ação revolucionária" (Freud, 1932/1976, p. 218) . Por ter destrinchado 
como ninguém a lógica do capitalismo, Marx sabia que nenhuma regulação extrínseca ao processo econômico (nenhuma regulação ideológica ou moral, por exemplo) poderia por si só limitar o processo. E apostava na ação revolucionária como a força que levaria à substituição da produção capitalista por outro modo de produção onde a mais-valia fosse revertida de modo mais justo, ou nas palavras dele: "de cada qual segundo as suas capacidades" e "a cada um segundo suas necessidades" (Marx, 1891[1921]/1971, p. 21).

Já a psicanálise não pode encampar este programa marxista. Se de um lado se constata que os interesses dos homens são regulados por fatores econômicos, como mencionamos, por outro lado a experiência psicanalítica demonstra que uma transformação que opere meramente na esfera econômica não basta para operar efeitos significativos no que diz respeito à limitação destes interesses em benefício da vida em sociedade. Ao contrário de Marx, o que se observa na clínica evidencia justamente que, não importa quão terrível seja o preço a pagar, nem por isso o homem está em princípio disposto a sacrificar seu gozo por um ato que o situe como sujeito. 0 que a psicanálise distinguiu de mais decisivo foi, justamente, que neste ponto, o que vigora é um posicionamento ético. Isto situa a limitação do gozo num plano contingente, impossível de comandar, impossível de regular totalmente pela educação ou pela moral. E também é isso que torna impossível à psicanálise, encampar o impulso proselitista.

Não há como apostar numa revolução de massas quando se reconhece de saída que não há como "revolucionar" de forma cabal nossa relação ao mais-de-gozar. Lacan demonstra aliás, que a própria função de mais-de-gozar assumida pelo objeto $a$ é reiterada incessantemente em nossas estratégias (mais ou menos suicidas) de recuperação do que é (desde sempre) perdido por força da divisão introduzida pela linguagem. Além disso, se concordamos todos que "não é suficiente apenas interpretar o mundo" (Marx \& Engels, 1845/2010, p. 124), é tempo, no entanto, de aprendermos com Lacan que a questão de "transformá-lo" não é tão imediata quanto como supunham Marx e Engels. Ou antes, que para "transformar o mundo" não basta denunciar o sintoma do capitalismo. Não se pode deter o sintoma com conscientização, com moralidade e nem pela correção. Para deslocar algo do sintoma que está estruturado, é preciso antes lancetar o gozo que concerne ao sujeito, dando lugar ao real que ali se encontra eclipsado.

O legado de Lacan para conduzir a psicanálise diante desta conjuntura (cujos desdobramentos, por assim dizer, ele previu) foi o objeto mais-de-gozar. O objeto que liga a dimensão do sujeito à topologia de seu gozo perdido. Inseparável do discurso analítico, que o engendra e o recolhe como efeito, este objeto aglutina nossos "meios de produção" de satisfação. E é neste ponto, na medida em que os efeitos reais da linguagem articulam no corpo toda uma economia, na medida em que esse objeto toma a forma das possibilidades novas de gozo asseguradas pela tecnociência como produto a ser consumido no mercado dos bens, que a psicanálise é chamada a intervir. O problema, como dissemos é global e especifica algo essencial 
em nosso tempo. Mas é somente no plano local do sintoma e dos dramas que ele enseja - e não no plano do sistema - que o jogo do gozo pode ser alterado.

A condição da psicanálise - mais ainda hoje do que sempre, mais ainda entre nós, neste tempo de discursos tão acirrados - é ingrata porque se trata de propor ao falante suportar a dimensão de uma perda, sem se constituir ela mesma (a psicanálise) como mais uma religião, um saber ou um sistema. No Brasil contemporâneo é fundamental assumir que a intervenção da psicanálise não pode se dar como mais uma militância - como tantas a que estamos expostos. Nossa tarefa está atrelada ao ordinário, aos dramas concretos do cotidiano, na medida em que se trata de tratar ali, no plano do discurso banal e em nível de nossas práticas, a finitude e a continuidade da cultura como determinados por uma perda real que opera a partir da linguagem. 0 que pode introduzir alguma limitação na determinação econômica do gozo que nos concerne - e constitui nossa vida subjetiva e social - não é pois uma ação revolucionária e nem um a priori estipulado conceitualmente (como seria o caso para mais uma filosofia). O que a psicanálise pode introduzir é somente isto que Lacan (1964/1985) destacou como "presença do psicanalista". Presença que surge num ponto determinado da história, quando certas condições estão presentes e se pode atingir um certo limiar, mas que requer ser sustentada de novo a cada vez, por um que sustente com seu corpo, com suas palavras e com seu ato, as condições da psicanálise.

\section{Notas:}

${ }^{1} \mathrm{Na}$ conferência intitulada "A terceira", Lacan (1974) afirma que é necessário que a psicanálise fracasse: "La vérité s'oublie. Donc tout dépend de si le réel insiste. Seulement pour ça, il faut que la psychanalyse échoue".

${ }^{2}$ No Seminário De um Outro ao outro, Lacan problematiza explicitamente a existência (problemática, contingente e dependente de ato) da psicanálise. "Quanto à psicanálise, [...], a questão é saber se ela existe" (LACAN, 1968-1969/2008, p. 31).

${ }^{3}$ No original, "Je n'en veux rien savoir".

${ }^{4}$ Recuperado de https://www.youtube.com/watch?v=YPnxqgFrpw8.

${ }^{5}$ Como se diz das frases improvisadas que aparecem na fala de um ator numa peça de teatro.

${ }^{6}$ Marx destacou como "fetichismo da mercadoria" a conjuntura na qual o valor de uma certa mercadoria, que de fato é decorrente de uma rede de relações sociais, assume uma forma "naturalizada" (ou, como prefere Marx, uma "forma fantasmagórica"). Aí, "uma relação social definida entre os homens", ou seja, a divisão do trabalho, fica oculta como se se tratasse de uma "relação entre coisas" e suas propriedades ou características materiais (Marx,1867[1890]/1998, p. 94).

7 "[...] a recente descoberta da importância extraordinária das relações econômicas trouxe consigo a tentação de não deixar que as alterações nelas ficassem entregues, mas sim de pô-las em execução pela ação revolucionária" (Freud, 1932/1976, p. 218). 


\section{Referências Bibliográficas}

Costa-Moura, F. \& Lo Bianco, A. C. (2006). A psicanálise fracassa onde a religião triunfa: em torno do real e da ciência. In Tempo Psicanalítico, (38). Rio de Janeiro: SPID.

Costa-Moura, F. (2010). O fracasso normal da psicanálise: o real e a função do analista. In Birman, J.; Fortes, I. \& Perelman, S. (Orgs.). Um novo lance de dados - psicanálise e medicina na contemporaneidade. Rio de Janeiro: PGTP.

Costa-Moura, F. \& Fernandes, F. L. (2011). A psicanálise existe? Considerações sobre o materialismo da psicanálise. In Lo Bianco, A. C. (Org.) A materialidade da psicanálise. Rio de Janeiro: Contracapa, 2011.

Freud, S. (1976). Projeto para uma psicologia científica. Edição standard brasileira das obras psicológicas completas de Sigmund Freud (Vol. 1). Rio de Janeiro: Imago (Trabalho original publicado em 1895[1950]).

Freud, S. (1976). Os chistes e sua relação com o inconsciente. Edição standard brasileira das obras psicológicas completas de Sigmund Freud (Vol. 8). Rio de Janeiro: Imago (Trabalho original publicado em 1905).

Freud, S. (1976). Os instintos e suas vicissitudes. Edição standard brasileira das obras psicológicas completas de Sigmund Freud (Vol. 14). Rio de Janeiro: Imago (Trabalho original publicado em 1915).

Freud, S. (1976). O mal-estar na civilização. Edição standard brasileira das obras psicológicas completas de Sigmund Freud (Vol. 21). Rio de Janeiro: Imago (Trabalho original publicado em 1930[1929]).

Freud, S. (1976). Novas conferências introdutórias sobre psicanálise. Conferência XXXV: a questão de uma Weltanschauung. Edição standard brasileira das obras psicológicas completas de Sigmund Freud (Vol. 22). Rio de Janeiro: Imago (Trabalho original publicado em 1932).

Freud, S. (1976). Análise terminável e interminável. Edição standard brasileira das obras psicológicas completas de Sigmund Freud (Vol. 23). Rio de Janeiro: Imago (Trabalho original publicado em 1937).

Lacan, J. (2008). O seminário, livro 7: a ética da psicanálise. Rio de Janeiro: Jorge Zahar (Trabalho original publicado em 1959-1960).

Lacan, J. (2005). O seminário, livro 10: a angústia. Rio de Janeiro: Jorge Zahar (Trabalho original publicado em 1962-1963).

Lacan, J. (2008). O seminário, livro 11: os quatros conceitos fundamentais da psicanálise. Rio de Janeiro: Jorge Zahar (Trabalho original publicado em 1964).

Lacan, J. (2008). O seminário, livro 16: de um Outro ao outro. Rio de Janeiro: Jorge Zahar (Trabalho original publicado em 1968-1969). 
Lacan, J. (1975). Le séminaire, livre XX: encore. Paris: Seuil (Trabalho original publicado em 19721973).

Lacan, J. (1974). "La troisième" - VII Congresso da Escola Freudiana de Paris (Roma 31/10 a 03/11 de 1974). Conferência inédita. Recuperado de http://www.valas.fr/Jacques-Lacan-LaTroisieme-en-francais-en-espagnol-en-allemand,011.

Marx, K. \& Engels, F. (2010). Teses sobre Feuerbach. A ideologia alemã: teses sobre Feuerbach (pp. 121-124). São Paulo: Centauro Editora (Trabalho original publicado em 1845).

Marx, K. (1998). O capital: crítica da economia política: livro I. Rio de Janeiro: Civilização Brasileira (Trabalho original publicado em 1867[1890]).

Marx, K. (1971). Crítica do programa de Gotha. Marx: critica do programa de Gotha, Engels: crítica do programa de Erfurt, Lenine: marxismo e revisionismo. Porto: Portucalense Editora (Trabalho original publicado em 1891[1921]).

Citacão/Citation: Costa-Moura, F. (nov. 2016 a abr. 2017). Para bom entendedor meia psicanálise não basta. Revista aSEPHallus de Orientação Lacaniana, 12(23), 23-32. Disponível em www.isepol.com/asephallus. doi: 10.17852/1809-709x.2019v12n23p23-32.

Editor do artigo: Tania Coelho dos Santos.

Recebido/Received: 05/02/2017 / 02/05/2017.

Aceito/Accepted: 27/02/2017 / 02/27/2017.

Copyright: (C) 2013 Associação Núcleo Sephora de Pesquisa sobre o moderno e o contemporâneo. Este é um artigo de livre acesso, que permite uso irrestrito, distribuição e reprodução em qualquer meio, desde que o autor e a fonte sejam citados/This is an open-access article, which permites unrestricted use, distribution, and reproduction in any medium, provided the author and source are credited. 